Sharif University of Technology
Scientia Iranica
Transactions E: Industrial Engineering
wCIENTIA

\title{
A quality improvement method for building materials and equipment based on quality gene
}

\author{
L.B. Sun ${ }^{\mathrm{a}, \mathrm{b}, *}$, S.S. Guo ${ }^{\mathrm{b}}$, D.R. Di ${ }^{\mathrm{a}}$, B. Ma $\mathrm{Ma}^{\mathrm{a}}$ and X.R. Huang ${ }^{\mathrm{c}}$ \\ a. Sinoma Technology \& Equipment Group Co., Ltd., Tianjin, 300000, China. \\ b. School of Mechanic and Electronic Engineering, Wuhan University of Technology, Wuhan, 430070, China. \\ c. School of Management and Economics, Hubei Polytechnic University, Huangshi 435003, China.
}

Received 8 May 2014; received in revised form 19 May 2015; accepted 10 May 2016

\section{KEYWORDS}

Quality gene;

Quality improvement;

Qenetic algorithm;

Quality gene

evolution.

\begin{abstract}
Good quality and low manufacturing cost are the two main factors for the enterprises to increase their core competitiveness. In order to reduce manufacturing cost and to promote quality of product, we propose a Quality Improvement (QI) method based on product quality gene evolution for building materials and equipment. First, we present the connotation of the product quality improvement based on quality gene. Second, the product quality gene evolution method based on genetic algorithm is adopted to achieve the product quality improvement. Finally, we use mill-type cylinder tube as an example to illustrate the proposed algorithm process. Experimental results have shown that the proposed approach is able to support quality improvement.
\end{abstract}

(C) 2016 Sharif University of Technology. All rights reserved.

\section{Introduction}

Good quality and low manufacturing costs are the two main factors for enterprises to increase their core competitiveness in today's globally competitive marketplace. In order to reduce manufacturing costs and to promote quality of product, continuous Quality Improvement (QI) method in manufacturing enterprises is necessary $[1,2]$.

Since building materials and equipment is large and production cycle is long, finding the complex inter-correlation in processes is important for QI in building equipment and materials for enterprises [35]. In the research field of quality management, most quality improvement methods have focused on customer satisfaction with the quality of product or on the monitoring of the core process of the product. Dhafr et al. [6] presented a developed methodology for quality improvement in manufacturing organizations

\footnotetext{
*. Corresponding author. Tel.: +86 022-26916783;

Fax: +86 022-26916783

E-mail address: sunliboyy@126.com (L.Sun)
}

by identifying various sources of quality defects on the product. Du et al. [7] proposed a stream of variation methodology to analyze, predict, and control the product quality in the complex multi-stage manufacturing systems. Villeta et al. [8] presented a novel link for the integration of the continuous improvement loop of measurement systems into the statistical quality control of manufacturing processes. Du et al. [9-11] proposed a few new methods to monitor and reduce process variation for quality improvement. The approaches mentioned above have discussed the connotation of product quality improvement, while they have failed to transform the market demand into specific parameters in the product design and manufacturing process, and the laws of product quality's evolution, emergence, and development have not been given much attention to in the literature.

The simple living cell and the human appearance on the earth are the result of biological evolution in adapting to the environment. there is no doubt that throughout the history of product quality development, product's long-term evolution is and has been changing society and environment. Therefore, there are striking 
similarities between the biological evolution process and the long-term evolution of product quality. Recently, genetic engineering has been widely applied for mechanical products. Sun et al. [12] proposed a quality prediction model to transform the quality prediction problem into the analysis of the mechanical product gene. Chen et al. [13] presented that the essence of the product and that of organisms is similar. In this paper, we will study genetic engineering and propose a quality gene evolution model to conduct a more indepth research on the product's manufacturing quality process.

The rest of the paper is organized as follows: In Section 2, we review the relevant literature related to quality improvement and quality gene, and the product quality improvement connotation based on quality gene is proposed in Section 3. Then, we introduce the product quality gene evolution method based on genetic algorithm in Section 4. Following this, a case study is used to illustrate the proposed algorithm process in Section 5. Finally, conclusions are given in Section 6 .

\section{Literature review}

In recent years, many researchers have focused on product's evolutionary design based on product gene. Chen et al. [13] have proposed a functional representation model based on verb-attributes. Gero et al. [14-16] have used genetic engineering to develop a number of computational models of creative designs. In [17], a gene evolution method has been proposed to distinguish different models. Gu et al. [18] have described a gene product model to represent and organize the product information. The aforementioned literature mainly discusses product design, and few researchers have made exploration on quality improvement in the manufacturing process. Generally, product gene only includes static design information instead of dynamic information, however, some dynamic information (i.e., manufacturing environment and quality characteristics) is very important to the evolutionary product.

As an extension of product gene, product quality gene is widely used for quality diagnosis and quality control in product manufacturing process. Sun et al. [12] have proposed a similarity analysis for the biological evolution and the manufacturing process. In [19], a quality diagnosis approach based on the similarity of product quality gene is proposed, and it is used to resolve the problems that the quality diagnosis, with respect to manufacturing process, is not effective. In [20], quality control theory based on quality gene is put forward to solve the problems that the quality information is complex and quality control is difficult in the manufacturing enterprises. These literatures have laid a foundation for the development of product quality gene theory. However, the quality improvements are not involved, and the quality improvement method is one of the driving forces to promote product design and manufacturing quality, while it can reduce the product defect rate and improve the enterprises' competitiveness.

\section{Product quality improvement connotation based on quality gene}

\subsection{The product quality gene}

The genetic information of living beings is stored in the chromosomes contained in their cells and the evolution of living beings is based on variations in their chromosomes [21]. In order to reform genes for product quality improvement, the quality genes are required to be disclosed similar to the features of biological genes. Moreover, their contents must be determined according to the quality attributes in the manufacturing processes. Therefore, the contents of the product quality gene include both genetic information and evolutionary information. Here, genetic information mainly refers to the content that can be cloned such as parts information, raw materials information, and hierarchical relationships information. Evolution information mainly refers to the quality characteristics which can be changed in the process such as roughness, size, etc.

The details of quality gene have been introduced in $[19,20]$. In [19], the product quality gene is defined with 5 tuples, i.e. S, T, F, V, and G respectively; they represent the product label information, process information, quality characteristics, quality characteristics precision, and quality characteristics affecting factors. In [20], a two-level gene code system for the product quality genes is proposed to describe the quality gene information.

\subsection{Storage and retrieval of product quality genes}

The storage and retrieval of product quality gene are the basis for quality improvement. Similar to the storage method of biological gene, which uses four elements $(\mathrm{A}, \mathrm{T}, \mathrm{C}$, and $\mathrm{G}$ ) to store their genetic information, in this paper, we propose a quality gene storage model (Figure 1). In Figure 1, product quality information is, firstly, converted into quality gene, and then, the gene codes are converted into binary sequences which are stored in the computer memory $[22,23]$. If necessary, the binary sequence can be copied or be translated into quality information.

\subsection{Product quality gene evolution}

The customer's demand for the product quality is often reflected in the quality characteristics. Therefore, to describe the quality gene evolution, the customer's 


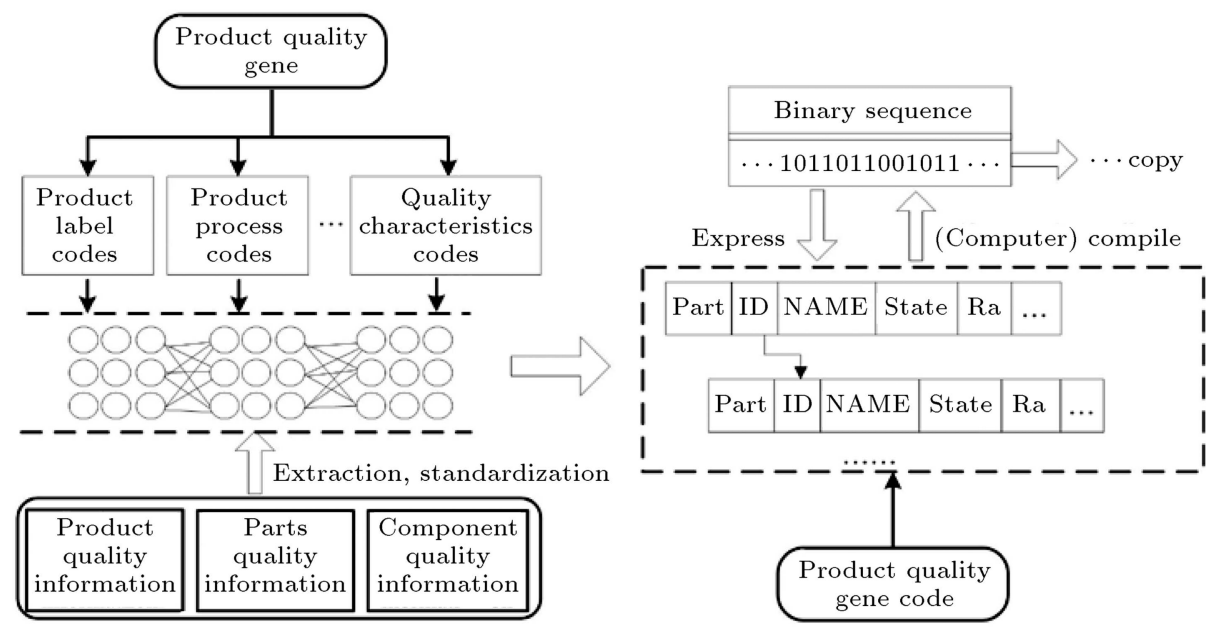

$$
\text { Symbolic: } \longrightarrow \begin{gathered}
\text { It means } \\
\text { containment } \\
\text { relationship }
\end{gathered} \bigcirc \begin{gathered}
\text { It means } \\
\text { gene element }
\end{gathered} \quad \begin{gathered}
\text { It means } \\
\text { correlation }
\end{gathered} \square \begin{gathered}
\text { It means } \\
\text { conversion } \\
\text { relationship }
\end{gathered}
$$

Figure 1. Product quality gene storage and retrieval model.

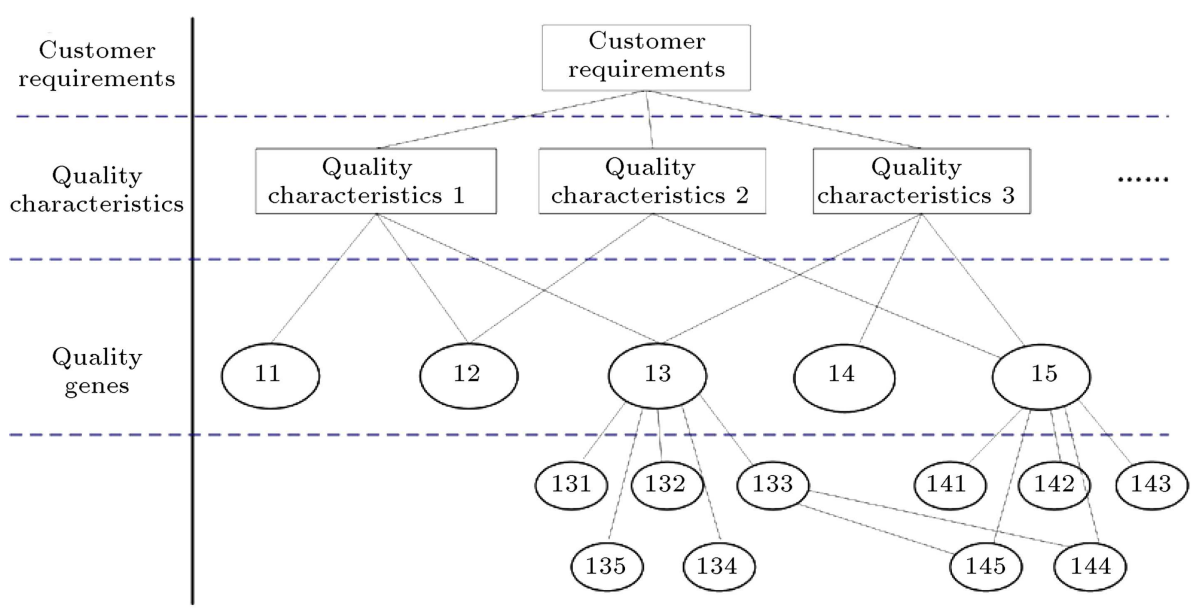

Figure 2. The mapping relation of customer's requirements, quality characteristics, and quality genes.

requirements should be converted into product quality gene element (Figure 2).

In Figure 2, the customer's requirements are related to quality characteristics, and the quality characteristics are determined by gene elements. According to the experts' experience or historical data, the customer's requirements in the first layer can be mapped into the gene elements in the bottom layer.

The gene elements have complex correlation with each other. For examples, the quality genes $\{144,145\}$ are related to the quality gene $\{133\}$, thus, the quality gene $\{144,145\}$ should be considered when the quality gene $\{133\}$ requires to be improved.

Being different from the biological evolution, the product quality gene cannot be evolved automatically, and they require artificial means. The offspring, which have better quality characteristics, will survive better in the changing society environment. In this paper, we propose a quality gene evolution process
(Figure 3), and the detailed analysis is described as follows:

- Step 1: Confirm the quality characteristics by the product quality gene evolution objectives. The market's and customer's requirements are converted to the need of product quality characteristics by experts' and technology's demand;

- Step 2: Identify the improved quality gene elements. According to the mapping relation between the product quality characteristics and quality gene elements, the quality characteristics are easy to convert into the quality gene elements;

- Step 3: Adopt the genetic algorithm to evaluate the product quality gene $[24,25]$. The detailed analysis is described in Section 4;

- Step 4: Rebuild the quality gene elements, and 


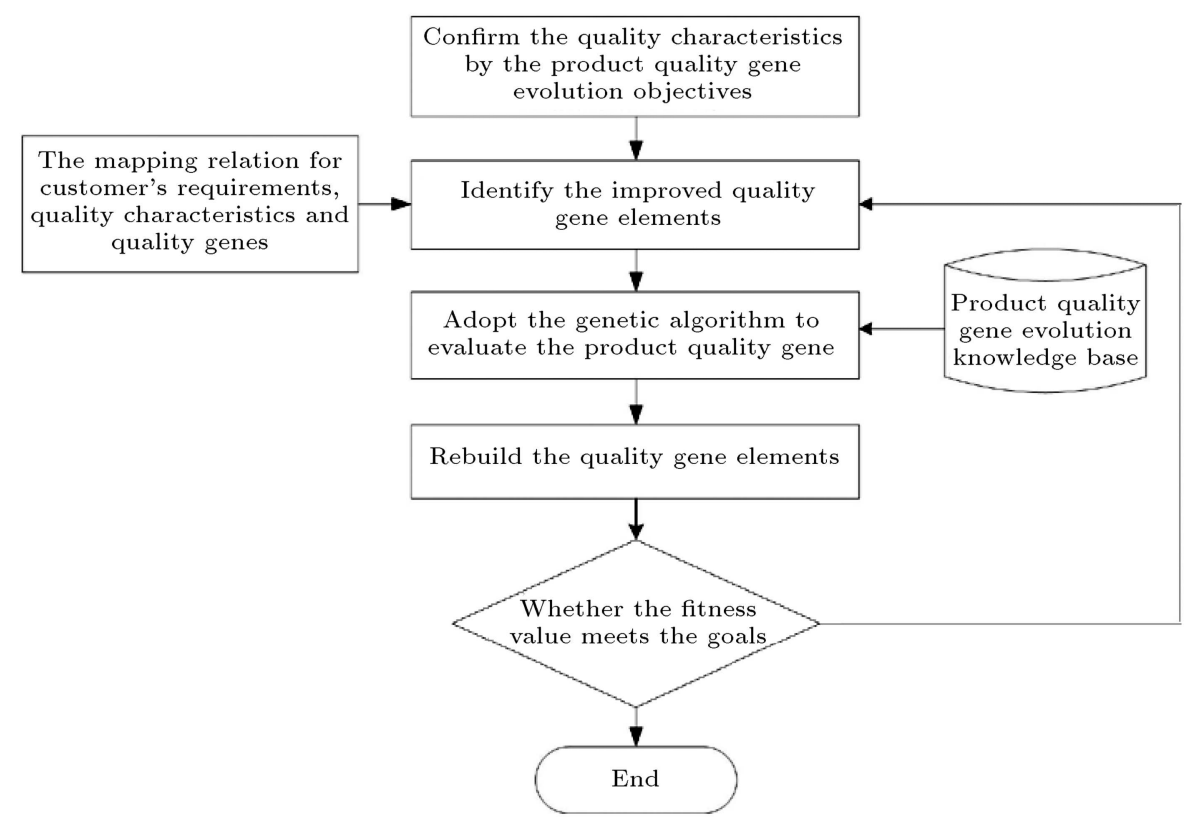

Figure 3. Quality gene evolution process.

judge whether the fitness value meet the evolutionary goals, if not, then jump to Step 2.

\section{Product quality gene evolution method based on genetic algorithm}

Many scholars have done a lot of methods for the optimal solution of a problem, such as gray theory [26], hybrid learning algorithm [27], Particle Swarm Optimization with Simulated Annealing-based selective neural network Ensemble (PSOSAEN) algorithm [2830], and Genetic Algorithm (GA) [31,32]. Genetic Algorithm (GA) is an intelligent optimization method, which in reference to the rule of "biological survival of the fittest", simulate the process of natural selection, crossover and mutation, and it searches for the optimal solution in the solution space. Due to its excellent characteristics of parallelism and global search, it is widely used for combinatorial optimization and scheduling $[31,32]$. Based on the above considerations, we believe that GA is more suitable for analyzing the product quality gene evolution.

\subsection{The basic elements of genetic algorithm}

In the traditional genetic algorithm, the crossover and mutation probability of chromosome is set in advance. However, due to the fact that the quality gene has some affinity, the probability will change in each process. In this paper, we propose an improved genetic algorithm based on affinity to achieve the product quality gene evolution. The basic elements of genetic algorithms are described as follows:

1. Chromosome code: The code is the basic element of the GA. The binary code is widely used as it is simple and easy; however, it has some disadvantages on the function of optimization. Real number code methods are widely used to solve the continuous parameter optimization problem, while the decimal code methods are used to solve the combinatorial optimization problems.

In this paper, the quality improvement belongs to a complex optimization problem with a larger search space. Therefore, decimal code is selected;

2. Initial population: The initial population is randomly generated by the product quality genes. Usually, the population size is 100 ;

3. Fitness function: The fitness is used to measure the individuals' excellent degree in optimization calculation, and the calculation method of the fitness function is described in detail in Section 4.2;

4. Selection operation: The selection operation is used to choose the populations which have been evaluated by the fitness function, and the population which has higher fitness will have more probability to be selected. In this paper, the roulette wheel approach is adopted as the select operator;

5. Crossover operation: The function of crossover operation is to take certain rules to exchange the individuals' elements and to produce a new individual. According to the characteristics of the product quality gene, in this paper, we adopt the multi-point crossover method (Figure 4).

Since the crossover between two similar chromosomes is not useful for gene evolution, inbreeding should be avoided to promote the quality genes' 


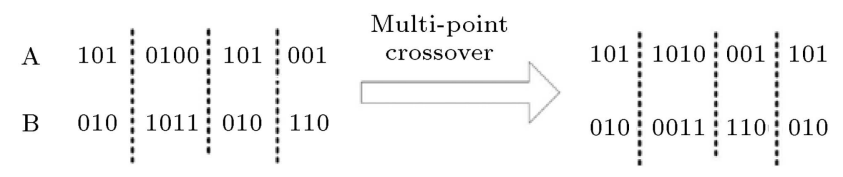

Figure 4. Quality genes multi-point crossover.

cross efficiency. Chen et al. [33] propose a "family tree" method to calculate the affinity between the genes. Sankoff and KruskaI [34] use sequence comparison method to estimate the degree of homology between two chromosomes. Because the product quality gene is virtual chromosomes, it is difficult to implement the sequence comparison. In this paper, we propose a method which is based on the genetic similarity to determine the affinity between the chromosomes. In Figure 5, the first generation of product quality gene contains 1.1-1.12 gene elements; the second generation of chromosomes contain 1.1, 2.2, 1.3-1.4, 2.5, 1.6-1.7, 2.8, $1.9 \sim 1.12$ elements, and in the selection process, the elements $1.2,1.5$, and 1.8 are eliminated.

In this paper, the affinity of quality genes $\mathrm{A}$ and $\mathrm{B}$ are described by the genetic similarity of quality genes A and B [19]. The gene element's affinity degree $G_{i}$ is described as Eq. (7).

$$
G_{i}=\left|1-\operatorname{sim}\left(A_{i}, B_{i}\right)\right| .
$$

Here, the $\operatorname{sim}\left(A_{i}, B_{i}\right)$ represent the similarity of quality gene elements $A_{i}$ and $B_{i}$.

The crossover probability $P_{i}$ of the $i$ th gene in the chromosomes can be calculated by Eq. (8). When the affinity between the elements $A_{i}$ and $B_{i}$ tends to 0 , the cross probability between the elements $A_{i}$ and $B_{i}$ tends to $\infty$.

$$
P_{i}=\left(G_{i}\right)^{-1}
$$

After the crossover probabilities of all genes have been determined, the probability $P_{i}$ can be normalized by Eq. (9).

$$
p_{i}^{*}=\frac{p_{i}}{\sum_{i=1}^{n} p_{i}}
$$

6. Mutation operation: The mutation operation has the same function as that of the crossover operation. It should be set in an appropriate range. If the mutation rate is too low, some useful information will not be selected; otherwise, if the mutation rate is too high, it is not recommended to optimize the results.

According to the definition of product quality genes $[19,20]$, in this paper, we use the same attributes of the gene elements to describe the mutation rate, and the definition of the same attributes of gene elements is described as follows:

Definition 1 uses the same attributes of gene elements: if the gene element is affected by the same factors, it means that the gene elements have the same attributes. For example, the working experience and manufacturing methods of one worker have the same attributes, because they are affected by the worker's length of service.

Assuming the $i$ th gene sets contain $C_{i}$ gene elements with the same attributes, then the quality gene's mutation rate $p_{m}^{i}$ is calculated as Eq. (10):

$$
p_{m}^{i}=\frac{C_{i}}{\sum C_{i}} .
$$

After the mutation probabilities of all genes have been determined, the probability $p_{m}^{i}$ can be normalized by Eq. (11):

$$
p_{m}^{i *}=\frac{p_{m}^{i}}{\sum_{i=1}^{n} p_{m}^{i}}
$$

7. Stop criterion: When the individual's fitness value reaches a given threshold, and the fitness value has little fluctuations in a certain range; the genetic algorithms will stop. Generally, the default number of iterations is $100-500$.

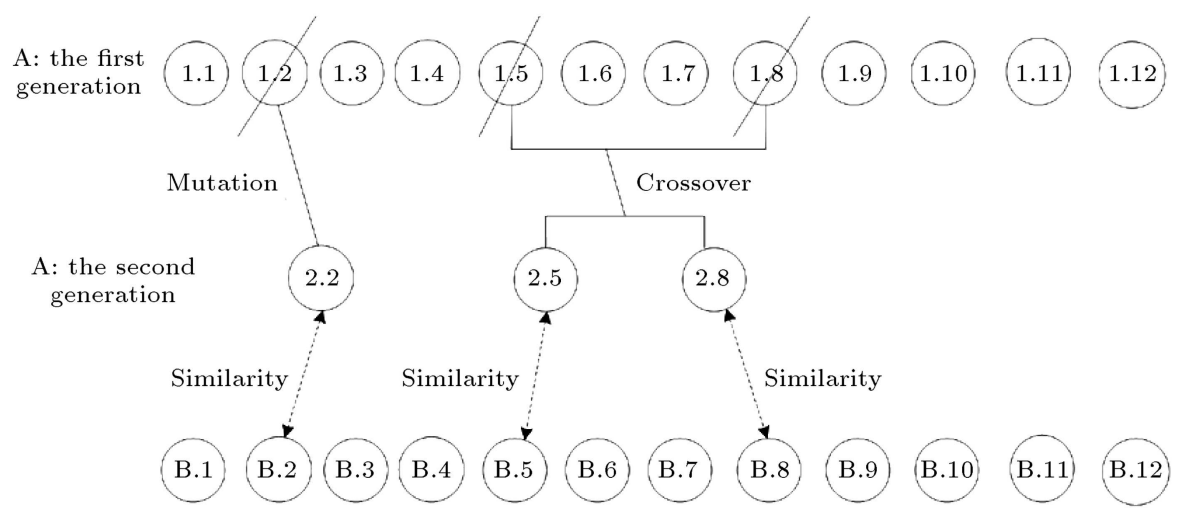

Figure 5. Analyses for the affinity between the quality genes. 


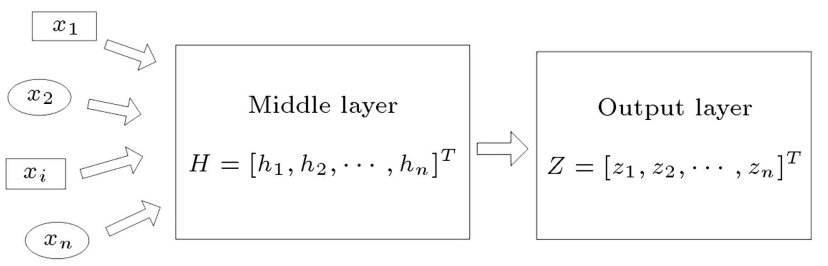

Figure 6. Quality gene's input and output model.

\subsection{Fitness function determination method}

The purpose of product quality gene evolution would help the enterprises occupy more market share and obtain more profits, however, in the process of evolution, the enterprises would pay for more manpower, material resources, and costs. In this paper, we propose an input and output model to describe the quality gene evolution process (Figure 6).

There are $N$ nodes in the input layer, $M$ nodes in the hidden layer, and $L$ nodes in the output layer. The nodes in the input layer are the product quality genes which require to evolve, they are represented in Eq. (12):

$$
X=\left[x_{1}, x_{2}, \cdots, x_{n}\right]^{T} .
$$

The middle layer of the node is the hidden layer of the product quality gene evolution process; it mainly refers to manpower, material resources, etc., and, can be represented in Eq. (13):

$$
H=\left[h_{1}, h_{2}, \cdots, h_{n}\right]^{T} .
$$

The nodes in the output layer are the product's performances such as cost, energy saving, working efficiency, manufacturability, durability, and reliability, and can be represented in Eq. (14):

$$
Z=\left[z_{1}, z_{2}, \cdots, z_{n}\right]^{T} .
$$

There is a mapping relationship between input layer and hidden layer, and one element's improvement will cause the middle hidden layer's change. For example, if the gene element's affecting factors are improved, we are required to promote the experience of workers, measuring tools, etc.

Assuming there is a linear relation between the input layer and hidden layer, the relations between individual elements are described in Eq. (15):

$$
\bar{h}_{i}=x_{i}^{\prime} \xi_{i} \quad \text { i.e. } \quad \xi_{i} \subset(0,1) .
$$

Here, $\bar{h}_{i}$ presents the changes in the middle hidden layer (i.e., the improvement numbers of measurement tools and worker training programs); $\xi_{i}$ presents the proximity between improvement gene element and the target; $x_{i}^{\prime}$ presents the hidden layer's quality gene impact factor.
The matrix relationship between middle layer and input layer is described as Eq. (16):

$$
\left[\begin{array}{c}
\bar{h}_{1} \\
\bar{h}_{2} \\
\vdots \\
\bar{h}_{n}
\end{array}\right]=\left(\begin{array}{cccc}
x_{11}^{\prime} & x_{12}^{\prime} & \cdots & x_{1 n}^{\prime} \\
x_{21}^{\prime} & x_{22}^{\prime} & \cdots & x_{2 n}^{\prime} \\
\vdots & \vdots & \vdots & \vdots \\
x_{n 1}^{\prime} & x_{n 2}^{\prime} & & x_{n n}^{\prime}
\end{array}\right)\left[\begin{array}{c}
\zeta_{1} \\
\zeta_{2} \\
\vdots \\
\zeta_{n}
\end{array}\right]
$$

There is, in addition, a possible mapping relation between middle layer and output layer elements. The improvement of element in the output layer such as costs, delivery time, and resource consumption would cause the middle hidden layer's change. For examples, training of workers will increase the labor costs; the improvement of measuring instruments would increase the cost of resources, etc.

Assuming there is a linear relation between the hidden layer and output layer, the relation between individual elements are described in Eq. (17):

$$
\bar{z}_{i}=\ell_{i} \bar{h}_{i}
$$

Here, $\bar{h}_{i}$ presents the value of the output layer elements; $\ell_{i}$ presents the middle layer's influence and on output layer.

The matrix relationship between output layer and middle layer are described in Eq. (18); the conversion relationship between the input layer and output layer is shown in Eq. (19):

$$
\begin{gathered}
{\left[\begin{array}{c}
\bar{z}_{1} \\
\bar{z}_{2} \\
\vdots \\
\bar{z}_{n}
\end{array}\right]=\left(\begin{array}{cccc}
l_{11} & l_{12} & \cdots & l_{1 n} \\
l_{21} & l_{22} & \cdots & l_{2 n} \\
\vdots & \vdots & \vdots & \vdots \\
l_{n 1} & l_{n 2} & & l_{n n}
\end{array}\right)\left[\begin{array}{c}
\bar{h}_{1} \\
\bar{h}_{2} \\
\vdots \\
\bar{h}_{n}
\end{array}\right],} \\
{\left[\begin{array}{c}
\bar{z}_{1} \\
\bar{z}_{2} \\
\vdots \\
\bar{z}_{n}
\end{array}\right]=\left(\begin{array}{cccc}
l_{11} & l_{12} & \cdots & l_{1 n} \\
l_{21} & l_{22} & \cdots & l_{2 n} \\
\vdots & \vdots & \vdots & \vdots \\
l_{n 1} & l_{n 2} & & l_{n n}
\end{array}\right)} \\
\left(\begin{array}{cccc}
x_{11}^{\prime} & x_{12}^{\prime} & \cdots & x_{1 n}^{\prime} \\
x_{21}^{\prime} & x_{22}^{\prime} & \cdots & x_{2 n}^{\prime} \\
\vdots & \vdots & \vdots & \vdots \\
x_{n 1}^{\prime} & x_{n 2}^{\prime} & & x_{n n}^{\prime}
\end{array}\right)\left[\begin{array}{c}
\zeta_{1} \\
\zeta_{2} \\
\vdots \\
\zeta_{n}
\end{array}\right] .
\end{gathered}
$$

Each element in output layer has different dimensions, and each element can be normalized by Eq. (20):

$$
f_{z i}=f\left(Z_{i}\right) / \sum_{i=1}^{n} f\left(Z_{i}\right) .
$$

The fitness function of the genetic algorithm can be represented in Eq. (21).

$$
F=\sum_{i=1}^{n} f\left(z_{i}\right) .
$$




\section{Case for product quality gene evolution method}

To illustrate the application of the proposed model and algorithm, we give an example concerning the milltype cylinder tube, which has a complex production process and a long cycle process. Consequently, it is necessary to analyze the quality evolution problems. The processes of cylinder are described in Table 1; its physical diagram is shown as Figure 7.

According to the product quality gene evolution process, firstly, the improved defect genes should be identified, then we analyze the optimal benignity of quality gene evolution based on the genetic algorithm.

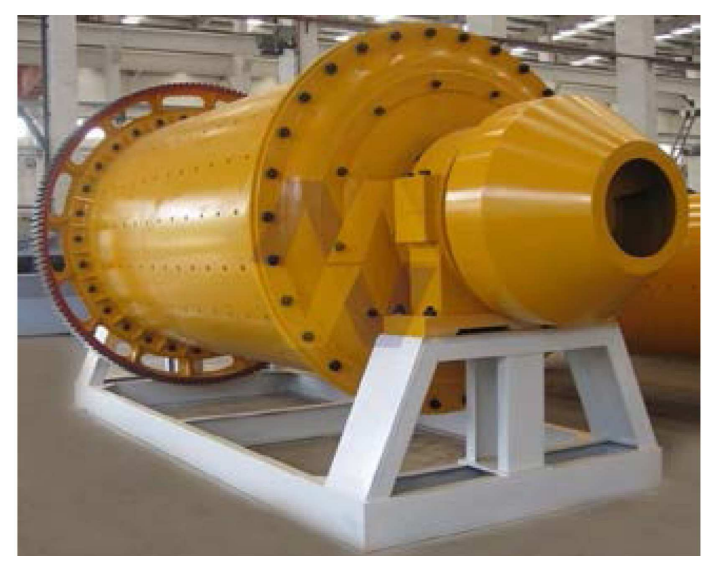

Figure 7. Physical diagram of cylinder.
Based on the above, we can judge whether the reorganization quality gene meets the customer's demand or not.

\subsection{Identify the cylinder gene defects}

According to the barrel crack is a common fault. It is clear that solving the barrel crack fault will enhance the enterprise's market share. Usually, the cause of barrel crack fault can be, mainly, divided into three aspects:

1. Tube structure design is not reasonable;

2. Cylinder welding quality is poor;

3. The shell thickness and strength is not enough.

According to the process flow in Table 1 and the product quality gene theory, the improved quality is analyzed as follows:

1. Cylinder's structure design is not reasonable. The product process quality gene should be improved such as reducing welding stress and bending stress of cylinder;

2. Cylinder's welding quality is poor. There are too many welding processes in the production process; therefore, it is required to improve within the field of the manufacturing process such as improving the environment temperature, environment dust, and improving the precision of welding equipment;

3. The shell's thickness and strength is not enough. The product quality genes' material properties

Table 1. Main processes of the cylinder.

\begin{tabular}{|c|c|c|}
\hline Num. & Technology content & The main content of quality testing \\
\hline 1 & Typesetting blanking & $\begin{array}{l}\text { Inspect the steel plate surface quality; cracks, } \\
\text { bubble, and scarring are not allowed; the steel } \\
\text { should not be layered. }\end{array}$ \\
\hline 2 & Welding & Internal welding angle should be less than $1 \mathrm{~mm}$. \\
\hline 3 & Blanking & $\begin{array}{l}\text { The parallelism should be } \pm 1 \mathrm{~mm} \text {; diagonal } \\
\text { deviation should be less than } 1.5 \mathrm{~mm} \text {; diagonal } \\
\text { deviation is less than or equal to } 1.5 \mathrm{~mm} \text {. }\end{array}$ \\
\hline 4 & Roll roundness correction & $\begin{array}{l}\text { The biggest clearance between model and } \\
\text { barrel should not be more than } 2 \mathrm{~mm} \text {. }\end{array}$ \\
\hline 5 & Cylinder welding & $\begin{array}{l}\text { Welding wire, flux, and flaw detection should } \\
\text { meet the requirements. }\end{array}$ \\
\hline 6 & Manhole paragraph & $\begin{array}{l}20 \mathrm{~mm} \text { allowance should be left when cutting } \\
\text { machining. }\end{array}$ \\
\hline 7 & Manhole process & Surface roughness should be less than 3.2 . \\
\hline . & $\cdots$ & $\cdots$ \\
\hline$n$ & Paint & The paint quality requirements should be detected. \\
\hline
\end{tabular}


should be modified such as increasing the steel plate's thickness and material.

According to the above analysis, the cylinder's default quality gene code is described as follows:

$$
p q g_{q}=(470,275,30,0.05,2,150) .
$$

Here, " 470 " represents the cylinder's welding stress; "275" represents the cylinder's bending stress; " 30 " represents the environment temperature; " 0.05 " represents the dust degrees; "2" represents the welding equipment's precision grades; and "150" represents the thickness of steel plate.

\subsection{Quality gene improvement analysis for cylinder based on genetic algorithm}

1. Initial population: The initial population can be set as 100 .

2. Fitness function determination: The input layer can be confirmed according to the product's improving quality of genetic elements, $\left[x_{1}, x_{2}, x_{3}\right.$, $\left.x_{4}, x_{5}, x_{6}\right]$.

In this paper, the factors of the middle hider layer for cylinder maily include: the number of technicians, the number of workers, the number of inspector, the inspection batch and raw material weight, which are described as $H$ :

$$
H=\left[h_{1}, h_{2}, h_{3}, h_{4}, h_{5}\right] .
$$

Due to the role of the middle hider layer, in this paper, the factors of output layer for cylinder maily include: manufacturing cost, resource consumption, and delivery time, which are described as $Z$ :

$$
Z=\left[z_{1}, z_{2}, z_{3}\right] .
$$

According to Eq. (16), the target of the gene was defined as $430,245,28,0.01,4,200$. The target genes correspond with the output layer gene.

Since the impact factors $x_{i}^{\prime}$ and $\ell_{i}$ are associated with the market and social factors respectively, the impact factors can be obtained based on expert's experience. This paper assumes that the impact factors are shown as follows:

$$
x_{i}^{\prime}=\left(\begin{array}{cccccc}
3 & 3 & 1 & 1 & 2 & 3 \\
1 & 1 & 4 & 1 & 2 & 1 \\
3 & 3 & 3 & 2 & 4 & 2 \\
2 & 3 & 2 & 3 & 4 & 3 \\
2 & 2 & 1 & 1 & 2 & 5
\end{array}\right) .
$$

Here, the first line presents input layer quality genes to a middle layer gene element $h_{1}$ (technicians' number), and the second line presents input layer quality genes to a middle layer gene element $h_{2}$ (number of workers), etc.

$$
\ell_{i}=\left(\begin{array}{ccccc}
300 & 200 & 300 & 200 & 50 \\
5 & 4 & 5 & 18 & 12 \\
2 & 1.8 & 2 & 1.6 & 1.2
\end{array}\right)
$$

Here, the first line presents the impact factor that the middle layer gene element is on output layer quality genes $z_{1}$ (manufacturing cost), the second line presents the impact factor that the middle layer gene element is on output layer quality genes $z_{2}$ (resource consumption), and the last line presents the impact factor that the middle layer gene element is on output layer quality genes $z_{3}$ (delivery date).

$$
\begin{aligned}
{\left[\begin{array}{l}
\bar{z}_{1} \\
\bar{z}_{2} \\
\bar{z}_{3}
\end{array}\right] } & =\left(\begin{array}{ccccc}
300 & 200 & 300 & 200 & 50 \\
5 & 4 & 5 & 18 & 12 \\
2 & 1.8 & 2 & 1.6 & 1.2
\end{array}\right) \\
& \left(\begin{array}{llllll}
3 & 3 & 1 & 1 & 2 & 3 \\
1 & 1 & 4 & 1 & 2 & 1 \\
3 & 3 & 3 & 2 & 4 & 2 \\
2 & 3 & 2 & 3 & 4 & 3 \\
2 & 2 & 1 & 1 & 2 & 5
\end{array}\right)\left[\begin{array}{llll}
\zeta_{11} & \zeta_{12} & \cdots & \zeta_{1 n} \\
\zeta_{21} & \zeta_{22} & \cdots & \zeta_{2 n} \\
\zeta_{31} & \zeta_{31} & \cdots & \zeta_{3 n} \\
\zeta_{41} & \zeta_{42} & \cdots & \zeta_{4 n} \\
\zeta_{51} & \zeta_{52} & \cdots & \zeta_{5 n} \\
\zeta_{61} & \zeta_{62} & \cdots & \zeta_{6 n}
\end{array}\right] .
\end{aligned}
$$

Here, $\zeta_{\text {in }}$ presents the proximity degree between evolution gene and the target. Assuming the output value of a single input gene is $f\left(Z_{i}\right)=\bar{z}_{1}$, the fitness function of GA can be described as shown in Eq. (23):

$$
F=\sum_{i=1}^{3}\left(f\left(Z_{i j}\right) / \sum_{j=1}^{m} f\left(Z_{i j}\right)\right) .
$$

To obtain the minimum target, the function target can be transformed as follows:

$$
F^{\prime}=1-\sum_{i=1}^{3}\left(f\left(Z_{i j}\right) / \sum_{j=1}^{m} f\left(Z_{i j}\right)\right) .
$$

3. The heredity and variation: According to the analysis for input layer element of the product quality and the continuity data of product quality gene elements, crossover rate can be expressed in Eq. (24).

$$
p_{i}^{*}=\frac{\left(1-\operatorname{sim}\left(A_{i}, B_{i}\right)\right)^{-1}}{\sum_{i=1}^{n}\left(\left(1-\operatorname{sim}\left(A_{i}, B_{i}\right)\right)^{-1}\right)} .
$$

There are no same properties among the 6 quality genes in the output layer; all the genes' mutation rates are the same, and usually, the mutation rate is set as 0.01-0.7. 


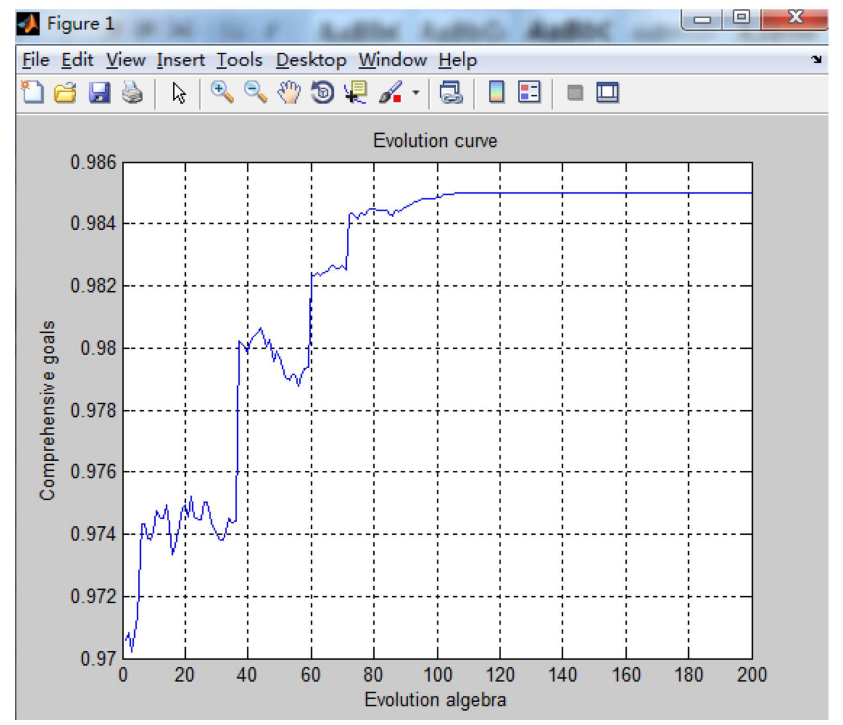

Figure 8. Evolution curve.

\subsection{Results analysis}

The above data are simulated in software Matlab, evolution curve is shown in Figure 8, and the algorithm is converged in the 110 th generation.

Based on the results, the fitness value of the optimal result is 0.985 , and the optimal individual genes are: 428, 245, 27.5, 0.03, 2, 150. Depending on the fitness values, the specific need in the middle layer which needs optimizing can be determined so as to illustrate the quality improvement of the tube mill barrel.

\section{Conclusions}

We present a quality improvement approach to promote the quality management in this research. An improved genetic algorithm based on affinity is proposed to achieve the product quality gene evolution. The experiment's results have shown that the proposed method can improve the company's quality management level, and reduce the implementation costs of the products.

\section{Acknowledgements}

This paper was supported by the Project of National Natural Science Foundation of China (No.71171154), the Fundamental Research Funds for the Central Universities (No.2012_YB_11), the National Natural Science Fund of China (NSFC.51375357).

\section{References}

1. Köksal, G., Batmaz, I. and Testik, M.C. "A review of data mining applications for quality improvement in manufacturing industry", Expert Syst. Appl., 38, pp. 13448-13467 (2011).
2. Veldman, J. and Gaalman, G. "A model of strategic product quality and process improvement incentives", International Journal of Production Economics, 149, pp. 202-210 (2014).

3. Sun, L.B., Guo, S.S., Huang, X.R. and Du, B.G. "Correlation analyses of process quality characteristics based on time-series cross-section approach", International Journal of Applied Mathematics and Statistics, 43(13), pp. 201-208 (2013).

4. Gijo, E.V. and Scaria, J. "Process improvement through six sigma with beta correction: A case study of manufacturing company", Int. J. Adv. Manuf. Technol., 71(1-4), pp. 717-730 (2014).

5. Jose, V.A., Fernando, R.S. and Julio, S.M. "Manufacturing variation models in multi-station machining systems", Int. J. Adv. Manuf. Technol., 64(1-4), pp. 63-68 (2013).

6. Dhafr, N., Ahmad, M., Burgess, B. and Canagassababady, S. "Improvement of quality performance in manufacturing organizations by minimization of production defects", Robotics and ComputerIntegrated Manufacturing, 22, pp. 536-542 (2006).

7. Du, S., Xi, L., Ni, J., Ershun, P. and Liu, C.R. "Product lifecycle-oriented quality and productivity improvement based on stream of variation methodology", Computers in Industry, 59, pp. 180-192 (2008).

8. Villeta, M., Rubio, E.M., Valencia, J.L. and Sebastián, M.Á. "Integrating the continuous improvement of measurement systems into the statistical quality control of manufacturing processes: A novel link", AnnalsManufacturing Technology, 61, pp. 507-510 (2012).

9. Du, S.C. and Lv, J. "Minimal Euclidean distance chart based on support vector regression for monitoring mean shifts of auto-correlated processes", International Journal of Production Economics, 141, pp. 377387 (2013).

10. Du, S.C., Huang, D.L. and Lv, J. "Recognition of concurrent control chart patterns using wavelet transform decomposition and multiclass support vector machines", Computers \& Industrial Engineering, 66, pp. 683-695 (2013).

11. Du, S.C., Lv, J. and Xi, L.F. "On-line classifying process mean shifts in multivariate control charts based on multiclass support vector machines", International Journal of Production Research, 50, pp. 6288-6310 (2012).

12. Sun, L.B., Guo, S.S., Li, Y.B. and Maw, M.H. "Quality prediction model based on mechanical product gene", Advanced Science, Engineering and Medicine, 5, pp. 1090-1096 (2013).

13. Chen, Y., Feng. P.E. and Lin, Z.Q. "A geneticsbased approach for the principle conceptual design of mechanical products", Int. J. Adv. Manuf. Technol., 27, pp. 225-233 (2005).

14. Gero, J.S. "Computational models of innovative and creative design processes", Technol. Forecast Soc. Chang, 64, pp. 183-196 (2000). 
15. Gero, J.S. and Nei, T.M. "An approach to the analysis of design protocols", Des Stud, 19, pp. 21-61 (1998).

16. Gero, J.S. and Kazakov, A.V. "Evolving design genes in space layout planning problems", Artif Intell Eng., 12, pp. 163-176 (1998).

17. Innan, H. and Kondrashov, F. "The evolution of gene duplications: classifying and distinguishing between models", Nat. Rev. Genet, 11, pp. 97-108 (2010).

18. Gu, X.J., Tan, J.R. and Qi, G.N. "Genetic model for mechanical product information", Chin. Mech. Eng., 8(2), pp. 77-79 (1997).

19. Sun, L.B., Guo, S.S., Tao, S.Q., Li, Y.B. and Guo, J. "A quality diagnosis method for the large equipments base on quality gene similarity", Int. J. Adv. Manuf. Technol., 69, pp. 2173-2182 (2013).

20. Sun, L.B., Guo, S.S. and Li, Y.B. "Research on quality control theory based on product quality genes", Chin. Mech. Eng., 24(21), pp. 2885-2890 (2013).

21. Winter, P.C., Hichey, G.I. and Fletcher, H.L., Instant Notes in Genetics, BIOS Scientific Publishers Limited, Oxford (1998).

22. Por, L.Y., Wong, K. and Chee, K.O. "UniSpaCh. A text-based data hiding method using unicode space characters", Journal of Systems and Software, 85(5), pp. 1075-1082 (2012).

23. Kyongsok, K. "A future direction in standardizing international character codes - with a special reference to ISO/IEC 10646 and Unicode", Computer Standards \& Interfaces, 14(3), pp. 209-221 (1992).

24. Mendel. Plant Hybridization Experiments [M], Beijing: Higher Education Press (1990).

25. Chen, K.Z. and Feng, X.A. "Computer-aided design method for the components made of heterogeneous materials", CAD Computer Aided Design, 35(5), pp. 453-466 (2003).

26. Liu, S. and Forrest, J. "The current developing status on grey system theory [J]", The Journal of Grey System, 2, pp. 111-123 (2007).

27. Du, S.C. and Xi, L.F. "A robust approach for root causes identification in machining processes using hybrid learning algorithm and engineering knowledge", Journal of Intelligent Manufacturing, 23, pp. 18331847 (2012).

28. Du, S.C. and Xi, L.F. "Fault diagnosis in assembly processes based on engineering-driven rules and PSOSAEN algorithm", Computers \& Industrial Engineering, 60, pp. 77-88 (2011).

29. Du, S.C. and Xi, L.F. "An integrated system for on-line intelligent monitoring and identifying process variability and its application", International Journal of Computer Integrated Manufacturing, 23(6), pp. 529542 (2010).

30. Shichang Du and Lifeng Xi. "On-line intelligent monitoring and diagnosis of aircraft horizontal stabilizer assemble processes", International Journal of Advanced Manufacturing Technology, 50(1-4), pp. 377389 (2010).

31. Shahram, S., Maghsud, S. and Iraj, M. "A multiobjective genetic algorithm for solving cell formation problem using a fuzzy goal programming approach", Int. J. Adv. Manuf. Technol., 70(9-12), pp. 1635-1652 (2014).

32. Mohammad, M. "A novel hybrid genetic algorithm to solve the sequence-dependent permutation flow-shop scheduling problem", Int. J. Adv. Manuf. Technol., 71(1-4), pp. 509-518 (2014).

33. Chen, K.Z., Zhang, X.W., Ou, Z.Y. and Feng, X.A. "Recognition of digital curves scanned from paper drawings using genetic algorithms", Pattern Recognition, 36(1), pp. 123-130 (2003).

34. Sankoff, D. and KruskaI, J., Time Warps, String Edits, and Macromolecules: The Theory and Practice of Sequence Comparison, Chicago, University of Chicago Press (1999).

\section{Biographies}

Libo Sun, a Doctor in Industrial Engineering, received his $\mathrm{PhD}$ degree and MS degree from Wuhan University of Technology, China. His research interests include production management, quality management, and information system.

Shunsheng Guo is a Professor in School of Mechanic and Electronic Engineering, Wuhan University of Technology, China. He received his MS degree from Zhejiang University, China, and his $\mathrm{PhD}$ degree from Wuhan University of Technology, China. His research interests include production management, quality management, and project management.

Dongren Di is a Professor-level Engineer in Sinoma Technology \& Equipment Group Co., Ltd, China. He received his BS degree from NanJing TECH University, China. His research interests include quality management and CAD theory.

Bin Ma is a Professor-level Engineer in Sinoma Technology \& Equipment Group Co., Ltd, China. He received his BS degree from Beijing University of Chemical Technology, China. His research interests include quality management and project management.

Xiaorong Huang is a Doctor in Industrial Engineering. He received his $\mathrm{PhD}$ degree and $\mathrm{MS}$ degree from Wuhan University of Technology, China. His research interests include Cloud Manufacturing, quality management, and information system. 